\title{
Magnitude Of Early Postoperative Hypoxemia And Its Associated Factors Among Adult Patients Who Undergo Emergency Surgery Under General Anesthesia At Jimma Medical Center, Jimma, Southwest Ethiopia, 2021. A Prospective Observational Study
}

Mitiku Berhanu (D96mitiku@gmail.com )

Jimma University

Negashu Dadi

Jimma University

Berhanu Mengistu Jimma University

Zemenu Muluken Jimma University

Ashenafi Tolossa Jimma University

Tajera Tageza Hawassa University

Megersa Kelbessa Jimma University Gezahegn Tesfaye Jimma University Belay Zewdie Jimma University

\section{Research Article}

Keywords: EPH, Postoperative recovery period, Circadian rhythm of lung and Jimma Medical Center Posted Date: February 21st, 2022

DOI: https://doi.org/10.21203/rs.3.rs-1358624/v1 
License: (c) (i) This work is licensed under a Creative Commons Attribution 4.0 International License. Read Full License 


\section{Abstract}

Purpose: Emergency Surgical procedures involve considerable risks. Among those, early postoperative hypoxemia $(\mathrm{EPH})$ is a frequent anesthetic complication in the post-anesthetic care unit (PACU). There is a great concern for EPH among health professionals; specifically, those providing emergency surgery during the nighttime. This raised anesthesia ended time-related risk of EPH question. Thus, this study aimed to determine the magnitude of EPH and its associated factors among adult patients who undergo emergency surgery under general anesthesia.

Methods: A prospective observational study through a consecutive sampling technique was conducted. Binary logistic regression analysis was used to identify associated risk factors. All variables that were found statistically significant on bivariable analysis were entered into a multivariable logistic regression analysis.

Result: Of 352 patients who undergone emergency surgery 149(42.3\%) patients were developed EPH. Factors significantly associated with EPH were anesthesia ended during night time (AOR=1.76, $95 \% \mathrm{Cl}[1.01,3.05], p=0.045)$, ASA III (AOR=12.35, 95\%Cl:[4.5, 34.02], $p=<0.001)$, age greater than 55(AOR= $3.2,95 \% \mathrm{Cl}:[1.7,5.91], p=<0.001)$, surgery duration greater than two hour $(A O R=2.012,95 \% \mathrm{Cl}:[1.2,3.51], p=$ $0.014)$, hypotension $(\mathrm{AOR}=10.3,95 \% \mathrm{Cl}:[2.4,44.16], \mathrm{p}=0.002)$, muscular strength score zero(AOR= $2.944,95 \% \mathrm{Cl}:[1.8,4.82], \mathrm{p}=<0.001)$ and preoperative oxygen saturation less than $95 \%(\mathrm{AOR}=2.371,95 \% \mathrm{Cl}$ : $[1.35,4.16], p=0.003)$.

Conclusion: The magnitude of EPH among patients who have undergone emergency surgery was high and thus recommended that oxygen should be provided timely to decrease it. Identified risk factors were night time ended anesthesia, ASA III, age greater than 55, surgery duration greater than two hours, hypotension, muscular strength score zero and preoperative oxygen saturation less than $95 \%$. This study found anesthesia ended during early morning favors early morning early postoperative hypoxemia (EMEPH). To avert EMEPH Anesthetist should avoid factors that favor the circadian rhythm of the lung based early morning anesthesia augmented EPH.

\section{Introduction}

Nowadays surgery under anesthesia, outcomes are becoming increasingly fine due to advancements in diagnosing, treating and preventing the adverse events that accompany anesthesia and surgery. However, surgical procedures still involve considerable risks. ${ }^{1,2}$ Among those, postoperative hypoxemia is the frequent anesthetic complication in the post anesthetic care unit (PACU), with incidences ranging from $14-80 \%{ }^{3-5}$

Early postoperative hypoxemia (EPH) is defined as insufficient oxygen in the blood. ${ }^{6}$ It can be appreciated by low arterial partial pressure of oxygen ( $\mathrm{PaO} 2$ ) level in the arterial blood less than $60 \mathrm{mmHg}$ or with the aid of pulse oximetry (SpO2) below 90\%. ${ }^{(7-9)}$ Many Perioperative factors may induce the development 
and progression of hypoxemia, such as preoperative underlying diseases, surgical injury, anesthetics, and postoperative respiratory events. ${ }^{(10)}$ Serious consequences, such as arrhythmias and abnormal blood pressure my follow hypoxemia. ${ }^{(11)}$ Severe hypoxemia has a potential to kill or leave the patient with devastating neurological handicaps, can cause neurological damage, increases unplanned Intensive care unit (ICU) admissions, morbidity, mortality, and hospital length of stay. ${ }^{(12-15)}$

Indeed there are different studies done pertaining to the incidence and associated factors of EPH, there are factors that are not studied at all with hypoxemia yet. The particular factor this study gave a due focus on was the time of the day anesthesia ended. Some clinical studies suggested that handling the

patients during the nighttime is linked to the worse outcome, favor the occurrence of complications. ${ }^{(16,17)}$ However, these studies didn't scrutinize specifically the incidence of EPH after nighttime emergency surgery, which was given due emphasis in this study.

Different studies found different factors account for EPH, broadly sorted as anesthesia, surgery and patient related factors. $(9,18)$ However, there is still a great concern for EPH among health professionals; specifically, those providing emergency health care for patients who undergo emergency surgery, even when there are no previously found significant factors. This is vividly evidenced when carrying out emergency surgery during the night time, and this raised time anesthesia ended related EPH question. Therefore, the robust motive that made us undertake this study was our high curiosity on the association of anesthesia ended during the nighttime with $\mathrm{EPH}$; which was not ever studied. So this study was aimed at generating sufficient knowledge concerning this aspect of hypoxemia after emergency surgery.

Moreover, up to the best of our knowledge, we can say there was nobody of paper studied EPH among patients who undergone emergency surgery only under General anesthesia (GA) with Endo-tracheal tube (ETT) exclusively.

\section{Methods}

Institution based, prospective observational study design was conducted at Jimma medical center (JMC), a tertiary teaching medical center located in Jimma town, Southwest of Ethiopia. The study was conducted from March 01 to May 30, 2021. All consecutive patients who were undergoing operation under GA with ETT during the study period were included in the study. Patients who were underwent emergency surgery under GA and not admitted to PACU, on oxygen therapy before surgery, sustained injury around the chest that could leads to hypoxemia (e.g. patients with pneumothorax) and patients who can't communicate were excluded from the study after verified by checking from their medical records and observations.

Independent factors included in the body of structured questionnaire were reached by reviewing the patient's charts and interviewing the patients. Anesthesia and surgery related data (e.g. type of volatile anesthetics, time of the day anesthesia administered, Intravenous (IV) anesthetics, intra-operative analgesia, duration and type of surgery and surgeon experience) was obtained from the anesthetic record 
sheet, patient's chart, and operation registration books. Patients were interviewed by the data collectors to self-report to socio-demographic factors and patient related factors of EPH. During interviewing the patients the questionnaire prepared in English was translated into Afan Oromo and Amharic, which are spoken by local community. Like other independent factors the time of the day anesthesia ended was collected from anesthesia chart too.

A manual pulse oximetry was used to record $\mathrm{SpO} 2$ during transferring the patient from operation room (OR) to PACU and in built pulse oximetry machine monitor was used to measure the dependent variable at PACU. Peripheral arterial oxygen saturation, heart rate (HR), blood pressure and body temperature were also recorded with the advent of patient monitor (except body temperature, which was recorded manually using thermometer) at PACU at admission and at 5-minute intervals for 20 minutes.

At the same time patient's sedation score $(0=$ agitated, $1=$ calm, alert, $2=$ sleepy and awaking after verbal command, $3=$ sleepy, awaking after tactile stimulation and $4=$ comatose $)$, ventilation score $(0=$ apnea, 1 $=$ limited breathing, respiratory obstruction, bronchospasm or HR below 8 breath per minute, and 2 = free breathing), muscular strength score ( $1=$ keeps grip for $>15$ seconds or $0=$ does not keep grip or keeps it for less than 15 seconds $)$ and verbal pain score $(0=$ no pain or no answer, $1=$ mild pain, $2=$ moderate pain and $3=$ severe pain) were recorded. ${ }^{(9)}$

Covid-19 infection prevention was implemented by all bodies (principal investigator, supervisor, data collectors and participants) involved in this study. This was achieved by using face mask, sanitizer after touching with patient's charts and other materials and practicing recommended physical distance. For data collectors Covid-19 infection prevention was part of training, as well as they were enforced to wear face mask during contact with participants to collect data. Appropriate hand hygiene before touching a patient and after touching a patient and patients surrounding was implemented by data collectors using water and soap.

Two BSc anesthetists and two Diploma nurse Anesthesia assistants were recruited, and one-day training was given on how to complete data collection, and they were supervised by the investigators and supervisors during data collection.

To measure the incidence of EPH the pulse oximetry (a small device that clips to patient finger or to a patient toes, in case the patient has no finger) was used. Pulse oximetry has become an essential technology to detect, treat, and reduce the degree of hypoxemia in the developed world. Pulse oximetry has been endorsed by the Canadian Anesthesiologists' Society, American Society of Anesthesiologists (ASA), World Federation of Societies of Anesthesiologists, and the WHO as a minimal monitoring standard during surgery. ${ }^{(19)}$ Reliably it monitors the peripheral oxygen saturation of the patient noninvasively.

Thus, in this study pulse oximetry was used to measure the presence of EPH among adult patients undergone different emergency surgery under general anesthesia at JMC. Consequently, clinically important EPH was defined as a pulse oximetry reading less than or equal to $92 \%$ at any time throughout 
the study time(starting from the time patient transferring to stretcher up to 20 minute in the PACU). A pulse oximetry reading with normal wave stay for more than 30 seconds was taken throughout the 20 minute, every 5 minute.

To ensure data quality, training and adequate orientation was given to for all data collectors. Then, the prepared format and questionnaire was given to data collectors. For validation of the questionnaire, a pretest was conducted on $5 \%$ of study participants at Shenen Gibe Hospital; Jimma Zone, two weeks before the actual data collection time, and few modifications were made. During data collection, regular supervision and follow up was provided by the principal investigator and the data was cross checked for completeness and consistency on daily basis. After the data collected checked for completeness, consistency and accuracy, it was entered into Epi-data software version 4.6.0.4 using data entry template.

\section{Operational Definitions}

\section{EPH}

Patients had been sorted as hypoxemic; if at any time during the observation period they were presented with $\mathrm{SpO} 2$ below or equal to $92 \%$ on room air for more than 30 seconds, and normoxaemic, if no SpO2 below $92 \%$ without oxygen therapy during the study period.

\section{Anesthesia ended time}

Time at which anesthesia ended was used to define it to nighttime and daytime.

Nighttime: Anesthesia ended between 8:00 pm - 7:59 am

Daytime: Anesthesia ended between 8: am - 7:59pm

\section{Evening}

6-9 pm

\section{Late evening}

9-midnight

\section{Late at night}

Midnight- 6 am

\section{Toward morning}

3-6 am 
6am-noon

\section{Early morning}

6-9 am

Mid- morning

8-10 am

\section{Late morning}

9 am-noon

Afternoon

noon $-6 \mathrm{pm}$

Early afternoon

noon - 3 pm

Mid-afternoon

2-4 pm

Late-afternoon

3-6 pm

\section{General anesthesia}

A combination of amnesia, analgesia, muscle relaxation and ETT.

\section{Transferring time}

is a time of moving the patient from OR table up to PACU arrival.

\section{Muscular strength score 1}

when the patient keeps hand grip for $>15$ seconds, while observing after let them to do so.

\section{Muscular strength 0}

when the patient does not keep hand grip or keeps it for less than 15 seconds, while observing after let them to do so. 
The minimum sample size required was calculated using a single population proportion formula as follows:

$n=\frac{N(\mathrm{Z} \alpha / 2) 2 P(1-P)}{d 2(N-1)+(\mathrm{Z} \alpha / 2) 2 P(1-P)}$, Where

$\mathrm{n}=$ Minimum sample size required for the study

$\mathrm{N}=$ Number of the study population, the annual number of patients undergone emergency surgery during the study period, which is 2650

$Z_{a / 2}=$ Confidence Interval $(\mathrm{Cl})$ at $95 \%$ which is 1.96

$d=$ Margin of error tolerated which is $(5 \%)$

$\mathrm{P}=50 \%$, Assumed incidence of EPH at JMC.

By substituting to the above formula, the minimum sample size required for the study was $=336$

Adding $5 \%$ of non- response rate, finally a total of 352 study participants were enrolled in the study.

Consecutive sampling technique was used i.e. all consecutive adult patients undergone emergency surgery under GA with ETT, who fulfilled inclusion criteria during the study period were included and recruited prospectively until the sample size would meet. The data was collected during the day and night time, as emergency surgery takes place at any time of the day.

Statistical data analysis was done using SPSS software version 22. Descriptive statistics were done and presented using tables and figures. Pearson Chi-square test was used to test the level of significance. A pvalue of less than 0.05 with a $95 \% \mathrm{Cl}$ was considered to constitute a statistically significant difference. Bivariable and multivariable binary logistic regressions were conducted to see the existence of the association between dependent and independent variables. All variables that were found to be statistically significant ( $p$ value less than or equal to 0.2 ) on bivariable analysis were entered into a multivariable logistic regression analysis to determine the significant independent predictors of EPH in those particular groups of patients.

The analyzed, compiled and organized data was compared and discussed. Consequently, the result was presented in tables, graphs and finally conclusions and recommendations were generated according to the result obtained.

Ethical clearance \& approval was obtained from the institutional review board of Jimma University and was brought to the office of JMC, OR head. Then a formal letter of permission to conduct the study was taken. Oral informed consent was also obtained from each study participant after a clear orientation of the study objective, benefit, and procedures. Confidentiality of participant's information was kept using 
unique codes and medical record numbers rather than personal identification. Moreover, the data collected from each study participant were used solely for the intended purpose.

\section{Results}

\section{Socio-demographic and clinical characteristics}

A total of 352 eligible patients had participated in this study. All of the sampled patients were responded to the interview (100\% response rate). Out of $352,59.4 \%$ were males. Around three fourth, $262(74.43 \%)$, of the participants age were less than 55. Majority of the patients, 236(67.05\%), during the study period were ASA class I patients. From 352 patients' undergone emergency surgery, the magnitude of EPH was $149(42.3 \%)$. Of patients greater than or equal to 55 years old $67(74.4 \%)$ showed the most frequent hypoxemia. The frequency of EPH was high, 22(81.5\%) among ASA III patients. Among sampled patients, subjects who had preoperative oxygen saturation less than ninety five experienced the most frequent $\mathrm{EPH}, 68(64.8 \%)$ (Table 1).

Table 1

Frequency distribution of socio-demographic and clinical characteristics with oxygen saturation status of the patient's undergone Emergency surgery under GA ( $N=352)$

\begin{tabular}{|c|c|c|c|}
\hline \multirow[t]{2}{*}{ Characteristics } & \multirow[t]{2}{*}{ Category } & \multicolumn{2}{|c|}{ Oxygen saturation status in percen } \\
\hline & & Normal & Hypoxemic (EPH) \\
\hline \multirow[t]{2}{*}{ Sex } & Male & $117(56.0)$ & $92(44.0)$ \\
\hline & Female & $86(60.1)$ & $57(39.9)$ \\
\hline \multirow[t]{2}{*}{ Age } & $<55$ & $180(68.7)$ & 82(31.3) \\
\hline & $\geq 55$ & $23(25.6)$ & $67(74.4)$ \\
\hline \multirow[t]{3}{*}{ BMI } & $<18.5$ & $39(60.0)$ & $26(40.0)$ \\
\hline & $18.5-24.9$ & 157(59.7) & $106(40.3)$ \\
\hline & $25-29.9$ & $7(29.2)$ & 17(70.8) \\
\hline \multirow[t]{3}{*}{ ASA } & ASA I & 174(73.7) & $62(26.3)$ \\
\hline & ASA II & $24(27)$ & $65(73.0)$ \\
\hline & ASA III & $5(18.5)$ & $22(81.5)$ \\
\hline \multirow[t]{2}{*}{ Preoperative oxygen saturation } & $\geq 95 \%$ & $166(67.2)$ & $81(32.8)$ \\
\hline & $<95 \%$ & $37(35.2)$ & $68(64.8)$ \\
\hline
\end{tabular}

\section{Incidence of EPH at different time of measurement}


From 352 patients' undergone emergency surgery, the magnitude of EPH was 149(42.3\%). Of 149 hypoxemic cases, EPH occurred during transferring the patients and immediately as the patients' admitted to PACU was high, $134(89.93 \%)$ and $129(86.58 \%)$ respectively. Low frequency, $34(22.82 \%)$ of $\mathrm{EPH}$ occurred during the last twenty minute. As the time increases beyond a twenty minutes the likelihood of EPH decreases (Fig. 1).

\section{Hypoxemia distribution with surgery and postoperative factors}

As showed in Fig. 2, majority of the patients were undergone emergency laparatomy and head surgery, $144(40.91 \%)$ and $53(15.06)$ respectively. The frequency of EPH was $15(78.9 \%)$ among patients undergone emergency relaparatomy. But, only one patient from ORMF surgery experienced EPH.

The incision site of majority of the surgeries was, upper and lower abdominal site, which accounts 158 (44.9\%). About 202(57.4\%) surgeries were taken greater than two hour. More than two third, $254(72.2 \%)$ of the patients were taken greater than $1500 \mathrm{ml}$ fluid. Around 294(83.52\%) of the patients had normal blood pressure. The frequency of EPH was high, 26(78.8\%) among patients with hypotension (Table 2). 196 patients had muscular strength score 1 , whereas 156 had muscular strength score 0 . The frequency of EPH was high (94(60.3)) among patients with muscular strength score 0 (Table 2). 
Table 2

Frequency distribution of surgery and postoperative factors with oxygen saturation status of patients undergone emergency surgery under GA $(N=352)$

\begin{tabular}{|c|c|c|c|}
\hline \multirow[t]{2}{*}{ Characteristics } & \multirow[t]{2}{*}{ Category } & \multicolumn{2}{|c|}{$\begin{array}{l}\text { Oxygen saturation status in } \\
\text { Percent }\end{array}$} \\
\hline & & Normal & Hypoxemic \\
\hline \multirow[t]{5}{*}{ Incision site } & Upper abdominal & $4(66.7)$ & 2(33.3) \\
\hline & Lower abdominal & $62(74.7)$ & $21(25.3)$ \\
\hline & Upper and lower abdominal & $72(45.6)$ & $86(54.4)$ \\
\hline & Limbs & $20(66.7)$ & 10(33.3) \\
\hline & Others (head, neck...) & $45(60)$ & $30(40)$ \\
\hline \multirow[t]{3}{*}{ Surgeon } & Senior & $5(62.5)$ & $3(37.5)$ \\
\hline & Resident & $170(57.4)$ & $126(42.6)$ \\
\hline & Both & $28(58.3)$ & $20(41.7)$ \\
\hline \multirow[t]{2}{*}{ Surgery duration } & $<120 \min$ & 107(71.3) & $43(28.7)$ \\
\hline & $\geq 120 \min$ & $96(47.5)$ & $106(52.5)$ \\
\hline \multirow[t]{2}{*}{ Fluid } & $<1500 \mathrm{ml}$ & $74(75.5)$ & $24(24.5)$ \\
\hline & $\geq 1500 \mathrm{ml}$ & $129(50.8)$ & $125(49.2)$ \\
\hline \multirow[t]{2}{*}{ EBL } & $<500 \mathrm{ml}$ & 184(61.5) & $115(38.5)$ \\
\hline & $\geq 500 \mathrm{ml}$ & 19(35.8) & $34(64.2)$ \\
\hline \multirow[t]{3}{*}{ BP } & Normal & $185(62.9)$ & 109(37.1) \\
\hline & Hypotensive & $7(21.2)$ & $26(78.8)$ \\
\hline & Hypertensive & $11(44)$ & $14(56)$ \\
\hline \multirow[t]{2}{*}{ Muscular strength } & Score 0 & $62(39.7)$ & $94(60.3)$ \\
\hline & Score 1 & 141(71.9) & $55(28.1)$ \\
\hline
\end{tabular}

\section{EPH and time anesthesia ended}

The incidence of EPH was more frequent among patients undergone surgery during the night time $82(46.6 \%)$ than day time, $67(38.1 \%)$. Anesthesia ended at early morning of night time was accompanied by high frequency of EPH, 18(90\%) (Fig. 3).

\section{EPH distribution with Anesthesia related factors}


The inhalational anesthetic used for majority, 238(67.6\%) of the surgeries was isoflurane. More than three fourth, 299(84.94\%) of the patients were taken both suxamethonium and Vecuronium for relaxation and reversal were given for majority of them, 314(89.2\%) (Table 3).

Table 3

Frequency distribution of anesthetic related factors with oxygen saturation of patients who undergone emergency surgery under GA at JMC from March 01 to May 30, 2021 ( $N=352$ )

\begin{tabular}{|c|c|c|c|}
\hline \multirow[t]{2}{*}{ Characteristics } & \multirow[t]{2}{*}{ Category } & \multicolumn{2}{|c|}{ Oxygen saturation status in percent } \\
\hline & & Normal & Hypoxemic \\
\hline \multirow[t]{3}{*}{ Inhalational anesthetics } & Halothane & $53(47.3)$ & $59(52.7)$ \\
\hline & Isoflurane & $149(62.6)$ & $89(37.4)$ \\
\hline & Both(halothane and isoflurane) & $1(50)$ & $1(50)$ \\
\hline \multirow[t]{4}{*}{ IV anesthetic drug } & Ketamine & $92(55.1)$ & $75(44.9)$ \\
\hline & Thiopentone & $49(62.8)$ & $29(37.2)$ \\
\hline & Propofol & $40(63.5)$ & $23(36.5)$ \\
\hline & Ketofol & $22(50)$ & $22(50)$ \\
\hline \multirow[t]{3}{*}{ Muscle relaxants } & Suxamethonium & $24(57.1)$ & $18(42.9)$ \\
\hline & Vecuronium & $5(45.5)$ & $6(54.5)$ \\
\hline & Both (Sux and vecuro) & $174(58.2)$ & $125(41.8)$ \\
\hline \multirow[t]{2}{*}{ Reversal (Neostigmine) } & Yes & $182(58)$ & $132(42)$ \\
\hline & No & $21(55.3)$ & $17(44.7)$ \\
\hline \multirow[t]{3}{*}{ Opioids } & Pethidine & $180(59.4)$ & $123(40.6)$ \\
\hline & Morphine & $18(46.2)$ & $21(53.8)$ \\
\hline & Tramadol & $5(50)$ & $5(50)$ \\
\hline
\end{tabular}

\section{Factors associated with EPH}

On analyzing in the bivariable analysis, 13 variables had $p$ value less than or equal to 0.2 and run into multivariate analysis, on which seven variables were continued to be associated with EPH ( $p$ value < 0.05). Six variables which were failed on analyzing with multivariate logistic regression include BMI, amount fluid given, EBL, type of procedures, pain and incision site. On multivariable analysis, ASA class III [(AOR, 95\% Cl) 12.35, (4.50-34.02)], preoperative oxygen saturation less than 95\% [(AOR, 95\% Cl), 2.371, (1.35-4.16)], age greater than 55 years [(AOR, 95\% Cl), 3.163, (1.7-5.91)], night time anesthesia ended $[(\mathrm{AOR}, 95 \% \mathrm{Cl}) 1.760,(1.01-3.05)]$, surgery duration greater than $120 \mathrm{~min}[(\mathrm{AOR}, 95 \% \mathrm{Cl}), 2.012,(1.2-$ 3.51)], muscular strength score 0 [(AOR, 95\%Cl), 2.944, (1.80-4.82)] and hypotension [(AOR, 95\%Cl), 10.3, (2.40-44.16)] demonstrated statistically significant association with EPH ( Table 4). 
Table 4

Bivariable and Multivariable Regression Analysis results show the independent risk factors of EPH among patients undergo emergency surgery at JMC, 2021( $\mathrm{N}=352)$

\begin{tabular}{|c|c|c|c|c|c|c|}
\hline \multirow[t]{2}{*}{ Variables } & \multirow[t]{2}{*}{ Category } & \multicolumn{2}{|c|}{ Frequency (\%) } & \multirow{2}{*}{$\begin{array}{l}\text { COR, } \\
(95 \% \mathrm{Cl})\end{array}$} & \multirow{2}{*}{$\begin{array}{l}\text { AOR, } \\
(95 \% \mathrm{Cl})\end{array}$} & \multirow{2}{*}{$\begin{array}{l}P \\
\text { value }\end{array}$} \\
\hline & & Normal & Hypoxemic & & & \\
\hline \multirow[t]{2}{*}{ ASA(III) } & Yes & $5(18.5)$ & $22(81.5)$ & $\begin{array}{l}2.27 \\
(0.64,8.1)\end{array}$ & $\begin{array}{l}12.35, \\
(4.50,34.02)\end{array}$ & $\begin{array}{l}< \\
0.001\end{array}$ \\
\hline & No & $198(60.9)$ & 127(39.1) & 1 & 1 & \\
\hline \multirow[t]{2}{*}{ Muscular strength } & Score 0 & $62(39.7)$ & $94(60.3)$ & $\begin{array}{l}1.84, \\
(0.99,3.42)\end{array}$ & $\begin{array}{l}2.944, \\
(1.80,4.82)\end{array}$ & $\begin{array}{l}< \\
0.001\end{array}$ \\
\hline & Score 1 & 141(71.9) & $55(28.1)$ & 1 & 1 & \\
\hline \multirow[t]{2}{*}{ Age } & $\geq 55$ & $23(25.6)$ & $67(74.4)$ & $\begin{array}{l}3.62 \\
(1.72,7.61)\end{array}$ & $\begin{array}{l}3.163 \\
(1.7,5.91)\end{array}$ & $\begin{array}{l}< \\
0.001\end{array}$ \\
\hline & $<55$ & $180(68.7)$ & $82(31.3)$ & 1 & 1 & \\
\hline \multirow[t]{2}{*}{$\begin{array}{l}\text { Preoperative oxygen } \\
\text { saturation }\end{array}$} & $<95 \%$ & $37(35.2)$ & $68(64.8)$ & $\begin{array}{l}2.72 \\
(1.38,5.35)\end{array}$ & $\begin{array}{l}2.371 \\
(1.35,4.16)\end{array}$ & 0.003 \\
\hline & $\geq 95 \%$ & $166(67.2)$ & $81(32.8)$ & 1 & 1 & \\
\hline \multirow[t]{2}{*}{ BP(hypotensive) } & Yes & $7(21.2)$ & $26(78.8)$ & $\begin{array}{l}9.15, \\
(1.79,46.82)\end{array}$ & $\begin{array}{l}10.3 \\
(2.40,44.16)\end{array}$ & 0.002 \\
\hline & No & $196(61.4)$ & 123(38.6) & 1 & 1 & \\
\hline \multirow[t]{2}{*}{ Surgery duration } & $\geq$ & $96(47.5)$ & $106(52.5)$ & $\begin{array}{l}2.53 \\
(0.74,8.6)\end{array}$ & $\begin{array}{l}2.012 \\
(1.2,3.51)\end{array}$ & 0.014 \\
\hline & 120min & 107(71.3) & $43(28.7)$ & 1 & 1 & \\
\hline \multirow[t]{2}{*}{$\begin{array}{l}\text { Time anesthesia } \\
\text { ended }\end{array}$} & Night & $94(53.4)$ & $82(46.6)$ & $\begin{array}{l}2.01, \\
(1.1,3.1)\end{array}$ & $\begin{array}{l}1.760 \\
(1.01,3.05)\end{array}$ & 0.045 \\
\hline & Day & $109(61.9)$ & 67(38.1) & 1 & 1 & \\
\hline
\end{tabular}

\section{Discussion}

The main finding of this study showed that the magnitude of EPH was $42.3 \%$. This finding was high compared with previous study conducted at Gondar (26.7\%). ${ }^{(20)}$ This high differences may be attributed to, due only emergency surgery, emergency surgery under general anesthesia with ETT and the cutoff point of SpO2 less than or equal to 92 were used in this study. Moreover, the current incidence was also high as compared with the study conducted in Canada(20\%). ${ }^{(21)}$ The possible reason might be, in the previous study less than $50 \%$ of the patients were transported with oxygen, which was not at all in the current study. A retrospective study done in China demonstrated that the incidence of EPH was $49.5 \%(5)$. 
However in the current study the incidence was lower. This variation might tantamount to the previous study subjects, who were undergone aortic dissection; highly risk patients.

In the current study, ASA III had a significant association with EPH. ASA class III patients were 12 times more likely to develop EPH than their counter parts. This finding was consistent with studies in Brazil, Thailand, Denmark. ${ }^{(9,22,23)}$ This could be because those patients, ASA class III, are associated with moderate to severe systemic disease such as respiratory system, cardiovascular system with greater risk of hypoxemia.

Moreover the current study revealed as muscular strength score 0 had a significant association with EPH. Patients with muscular strength score 0 were 3 times more likely to develop EPH than patients with muscular strength score 1. The result was in agreement with studies done in Qatar, Brazil and Ethiopia. ${ }^{(9,}$ $20,24)$ The amenable explanation may be due to the fact that muscular strength zero indicates as there is residual neuromuscular blockade which impair the muscles of respiratory system. ${ }^{(25)}$

Likewise, the current study vividly delineated that age greater than 55 had a significant association with EPH. Patients aged over 55 years were 3 times more likely to develop EPH than patients less than 55 years. This finding goes in line with previous studies done in China, India, Brazil and Colombia. $(9,10,12,26)$ The gradual decline of organ function and a residual NMB because of altered pharmacokinetics when there is diminished liver, heart and lung reserve. ${ }^{(27)}$ However the study conducted in Gondar, Ethiopia, did not found significant association of advanced age with $\mathrm{EPH} .{ }^{(20)}$ The possible reason might be, during the previous study regional anesthesia had been given for those patients, which put patients less likely to develop EPH. This is not an issue in the current study as it designed only for these patients undergo emergency surgery only under GA with ETT. Another possible explanation might be, in the previous study majority of the patients were undergone elective surgery.

In addition this paper also found that preoperative oxygen saturation less than $95 \%$ had significant association with EPH. Patients with preoperative oxygen saturation less than $95 \%$ were 2 times more likely to develop EPH than patients who were not. This is consolidated by prospective observational study done in India, which found that preoperative oxygen saturation less than $96 \%$ was an independent associated factor of EPH. ${ }^{(28)}$ The possible explanation underlie this might be, preoperative oxygen saturation less than $95 \%$ might be a surrogate of preoperative patients respiratory function impairment.

It is noteworthy, that the study also found surgery duration greater than two hour had a significant association with EPH. Study subjects undergone surgeries for greater than two hour were 2 times more likely to develop EPH than patients' undergone surgery for less than two hour in this study. This is consistent with the previous study done at Victoria General Hospital in Halifax, Canada, to identify risk factors of EPH and found that longer surgery duration was one of the significant risk factors. ${ }^{(29)}$

In this current body of paper hypotension also found as one of the significant predictor of EPH. Patients experienced hypotension was 10 times more likely to suffer from EPH. The study done in Denmark 
revealed that hemodynamic instability could cause EPH. ${ }^{(22)}$ However different studies done on elective surgery did not indentified hypotension as a significant association factor of EPH because the likelihood of hypotension in these patient is low due to optimization before surgery. But in case of emergency surgery as there is no sufficient time optimization before surgery is rare. Patients with hypotension experience hypoxemia due to hypo-perfusion. ${ }^{(30)}$

Excitingly, the current study found that night time, factor which was not ever studied with EPH, had significant association with EPH. Patients' undergone surgeries during the night time were 2 times more likely to develop EPH than their counterparts. Even if, there are no previous studies done regarding the $\mathrm{EPH}$ and time of the day anesthesia ended; we believe that the robust circadian rhythm of the lung is powerful enough to explain this finding. The pulmonary autonomic nerve supply has a circadian rhythmic activity. It has maximal parasympathetic activity in the early morning and maximal sympathetic activity in the late afternoon. This leads to a circadian rhythm in the bronchial tone with maximal bronchoconstriction about 6:00 AM and maximal bronchodilation at about 6:00PM. ${ }^{(31)}$ The anesthesia drug effect again may superimpose it. Expecting a more advanced future study on circadian rhythm of the lung and EPH, the current study advocates circadian rhythm of the lung favors early morning time anesthesia ended related risk of EPH, particularly early morning early postoperative hypoxemia (EMEPH).

\section{Study Strengths And Limitations}

Exhaustively collecting data during the day and nighttime among patients undergone emergency surgery under GA with ETT was one of the strength of this study. This enabled the study to found out new factor of EPH and adding new knowledge to the existing body of literature. The other strength of this study is that our findings will be evidence and prompt policy maker to pay attention to the area in providing the PACU with sufficient oxygen, thereby decreasing the incidence rate of EPH. Our study had Limitations too; firstly the study didn't follow these patients who developed EPH for long time to reach at secondary complications that accompany EPH. Another is that, this was a single institution study with a limited sample size and included only adult patients' undergone surgery at JMC and admitted PACU.

\section{Conclusion}

The finding of this study concludes as the magnitude of EPH was nearly half the study participants. Age greater than 55, muscular strength score 0 , ASA III, surgery duration greater than two hour, hypotension and preoperative oxygen saturation less than $95 \%$ were found to be factors significantly associated with $\mathrm{EPH}$. Additionally, the study found that anesthesia ended during night time was significantly associated with $\mathrm{EPH}$, particularly EMEPH. In culmination, the study concludes as there is anesthesia ended time related risk of $\mathrm{EPH}$, in addition to previously found predictors of $\mathrm{EPH}$.

\section{Abbreviations}


$A O R$, adjusted odds ratio; $E M E P H$, early morning early postoperative hypoxemia; $E P H$, early postoperative hypoxemia; ETT, endo-tracheal tube; GA, general anesthesia; JMC, jimma medical center; OR, operation room; PACU, postoperative care unit; $\mathrm{PaO2}$, arterial partial pressure of oxygen; $\mathrm{SpO2}$, pulse oximetry that measures oxygen saturation peripherally.

\section{Declarations}

\section{Ethics approval and consent to participate}

Ethical clearance \& approval was obtained from the institutional review board of Jimma University and was brought to the office of Jimma Medical Center, OR head. Then a formal letter of permission to conduct the study was taken. Oral informed consent was also obtained from each study participant after a clear orientation of the study objective, benefit, and procedures. Confidentiality of participant's information was kept using unique codes and medical record numbers rather than personal identification. Moreover, the data collected from each study participant were used solely for the intended purpose.

\section{Consent for publication}

Not applicable

\section{Availability of data and materials}

The datasets used and/or analysed during the current study are available from the corresponding author on reasonable request.

\section{Competing interests}

We have no competing interests.

\section{Funding}

We have no funding source.

\section{Author's contributions}

"M.B. conceived the problem under the study, wrote a statement of the problem and method part and performed analysis and wrote the main manuscript, N.D. wrote the background, B.M. wrote significance of the study and report, M.K, A.T, and T.T. conducted the literature review, data validation, data insertion and analysis, G.T. prepared tables and figures of report, Z.M and B.Z. wrote the discussion and conclusion. All authors reviewed the manuscript."

\section{Acknowledgments}

We would like to thank Jimma University Institute of Health Science for providing technical support. Likewise, we would like to thank all Anesthesia department staffs for their outstanding coordination and 
their great kindness in supporting us to undergo this study.

\section{References}

1. Faraj J, Corporation HM, Vegesna A, Corporation HM, Shaikh N, Corporation HM. Survey and management of anaesthesia related complications in PACU. 2012;(December).

2. Alexandra C, Caro B, Edwin F, Alvarado P, Torres M, Buitrago G, et al. Revista Colombiana de Anestesiología Guidelines and consensus Evidence-based clinical practice manual: Postoperative controls $\bowtie$. Colomb J Anesthesiol. 2015;43(1):20-31.

3. Canet J, Ricos M, Vidal F. Early postoperative arterial oxygen desaturation. Determining factors and response to oxygen therapy. Anesth Analg. 1989 Aug;69(2):207-212.

4. Moller JT, Wittrup M JS. Hypoxemia in the postanesthesia care unit: an observer study. Anesthesiology. 1990;73(5).

5. Wang $Y$, Xue S, Zhu H. Risk factors for postoperative hypoxemia in patients undergoing Stanford $A$ aortic dissection surgery. 2013;(2012027):1-7.

6. Morgan GE, Mikhail MS MM. clinical Anesthesiology. 5the ed. 2005.

7. Marcondes G, Ferreira EDA, Udelsmann A. Transportation of Patients to the Post-Anesthetic Recovery Room without Supplemental Oxygen: Repercutions on Oxygen Saturation and Risk Factors Associated with Hypoxemia. 2006;56:352-61.

8. Smith T, Pinnock P, Lin T. Smith T, Colin P TL. Postoperative managementFundamentals of Anaesthesia. 2016.

9. Filho O, De GR, Garcia JHS, Ghellar MR, Nicolodi MA, Boso AL et al. Factors associated to hypoxemia in the immediate postoperative period. Rev Bras Anestesiol. 2001;51:185-95.

10. Status $\mathrm{C}$. Incidence of hypoxemia in a post-anaesthesia care unit and relevant risk factors: a retrospective study of 14604 patients with general anaesthesia. :1-20.

11. Wheatley RG. Postoperative hypoxaemia: mechanisms and time course. 1990;45:566-73.

12. Maity A, Saha D, Swaika S, Maulik SG, Choudhury B. Anesthesia: Essays and Researches Detection of hypoxia in the early postoperative period. 2010;2010-3.

13. Uakritdathikarn T, Chongsuvivatwong V. Perioperative Desaturation and Risk Factors in General Anesthesia. 2008;91(7):1020-9.

14. Rose, D Keith and Cohen, Marsha M and Wigglesworth, Dan F and DeBoer DP. Critical Respiratory Events in the Postanesthesia Care UnitPatient, Surgical, and Anesthetic Factors. Anesthesiol J Am Soc 
Anesthesiol. 1994;81(2):410-8.

15. Lawrence VA, Hilsenbeck SG, Mulrow CD, Dhanda R, Sapp J, Page CP. Incidence and Hospital Stay for Cardiac and Pulmonary Complications after Abdominal Surgery.

16. Peberdy MA, Ornato JP, Larkin GL, Braithwaite RS, Kashner TM, Carey SM, et al. Survival From InHospital Cardiac Arrest During Nights and Weekends. JAMA. 2008 Feb;299(7):785-92.

17. Eskesen TG, Peponis T, Saillant N, King DR, Fagenholz PJ, Velmahos GC, et al. The American Journal of Surgery Operating at night does not increase the risk of intraoperative adverse events. Am J Surg. 2018;216(1):19-24.

18. Quintero-cifuentes IF, Pérez-lópez D. Colombian Journal of Anesthesiology Incidence of early postanesthetic hypoxemia in the postanesthetic care unit and related factors Factores relacionados e incidencia de hipoxemia postoperatoria temprana en la unidad de cuidados postanestésicos. 2018;46(4):309-16.

19. Nesthesia A, Anesthe DEL. Guidelines to the practice of anesthesia - Revised edition 2010. Can J Anesth. 2010;57:58-87.

20. Melesse DY, Denu ZA, Kassahun HG, Agegnehu AF. International Journal of Surgery Open The incidence of early post-operative hypoxemia and its contributing factors among patients underwent operation under anesthesia at University of Gondar comprehensive and specialized referral hospital , Gondar , North. Int J Surg Open. 2020;22:38-46.

21. Siddiqui N. hypoxemia on arrival to pacu: an observaional audit. 2014;(January 2006).

22. Jacob Trier Moller M witrup. Hypoxemia in the Postanesthesia Care Unit. Anesthesiology. 1990;(73).

23. Charuluxananan S. Risk Factors of Intraoperative Oxygen Desaturation: A Case-Control Study of 152 , 314 Anesthetics. 2007;90(11):2359-65.

24. Faraj JH, Vegesna ARR, Mudali IN, Khairay MA, Nissar S, Alfarhan M, et al. Survey and management of anaesthesia related complications in PACU. 2012;64-70.

25. Murthy HS, Jalaja KR, Ramachandra K, Parameshwara G. Postoperative Pulmonary Function. 2012; (6):1234-44.

26. Quintero-cifuentes IF, Pérez-lópez D. Colombian Journal of Anesthesiology Factores relacionados e incidencia de hipoxemia postoperatoria temprana en la unidad de cuidados postanestésicos Incidence of early postanaesthetic hypoxemia in the postanaesthetic care unit and related factors. 2018;46(4):30916. 
27. Murphy G, Szokol J, Avram M, Greenberg S, Shear T, Vender J, et al. Residual Neuromuscular Block in the Elderly: Incidence and Clinical Implications. Anesthesiology. 2015 Oct;123.

28. Kaushal A, Goyal P, Dhiraaj S, Agarwal A, Singh PK. Identification of Various Perioperative Risk Factors Responsible for Development of Postoperative Hypoxaemia. 2018;46(6).

29. Walker M, Farmer RG, Schelew B. Risk factors for oxygen desaturation on arrival in the postanesthesia care unit. 2015;5:1019-20.

30. BARASH, P. G., CULLEN, B. F., \& STOELTING RK. Clinical Anesthesia. 8th ed. Philadelphia: Lippincott.; 1986.

31. John E. Hall. Guyton and hall textbook of medical physiology. 12th ed. London, England: W B Saunders; 2015.

\section{Figures}

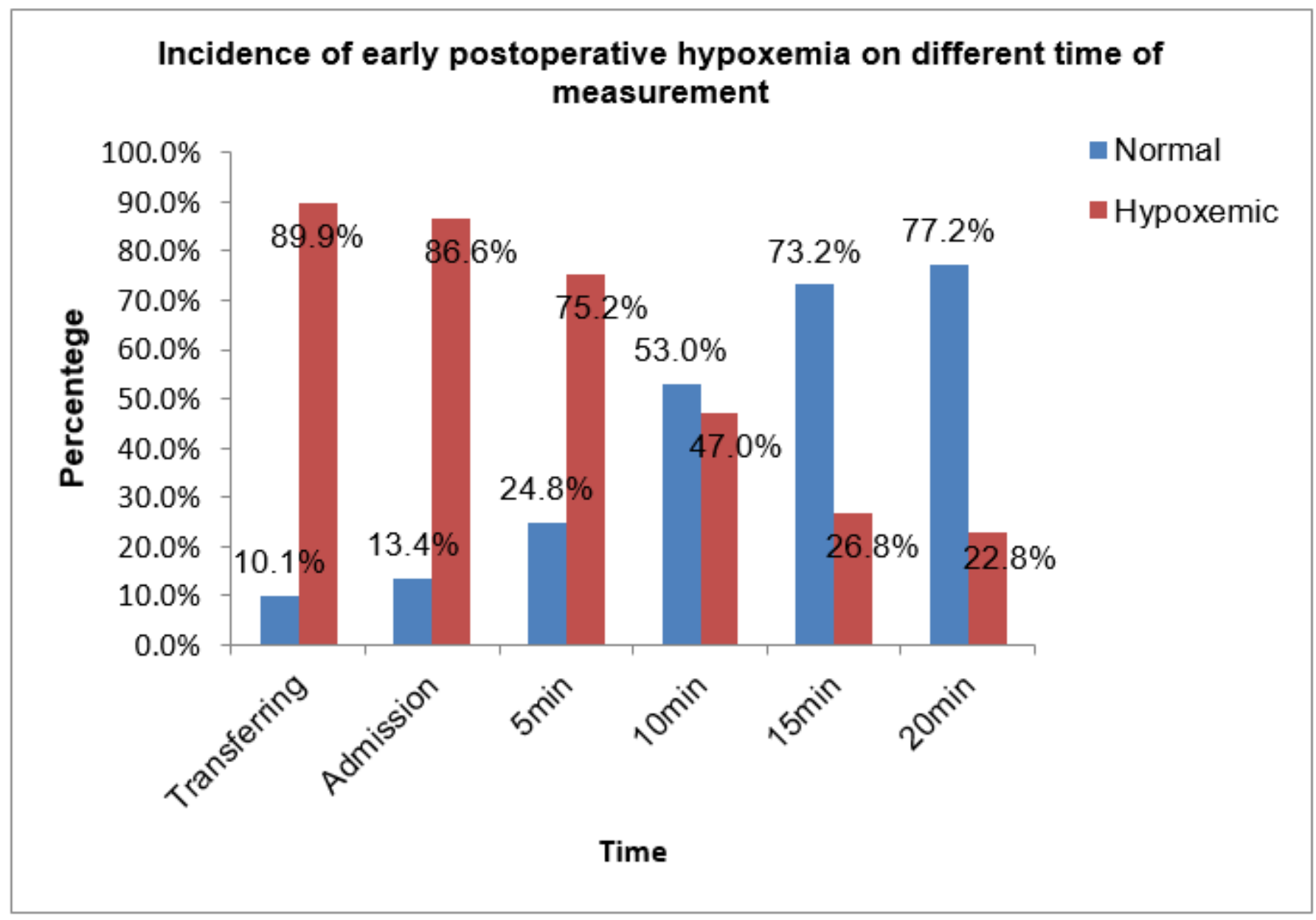

Figure 1 
Magnitude of EPH during different time of measurement in JMC, March 01 to May 30, 2021

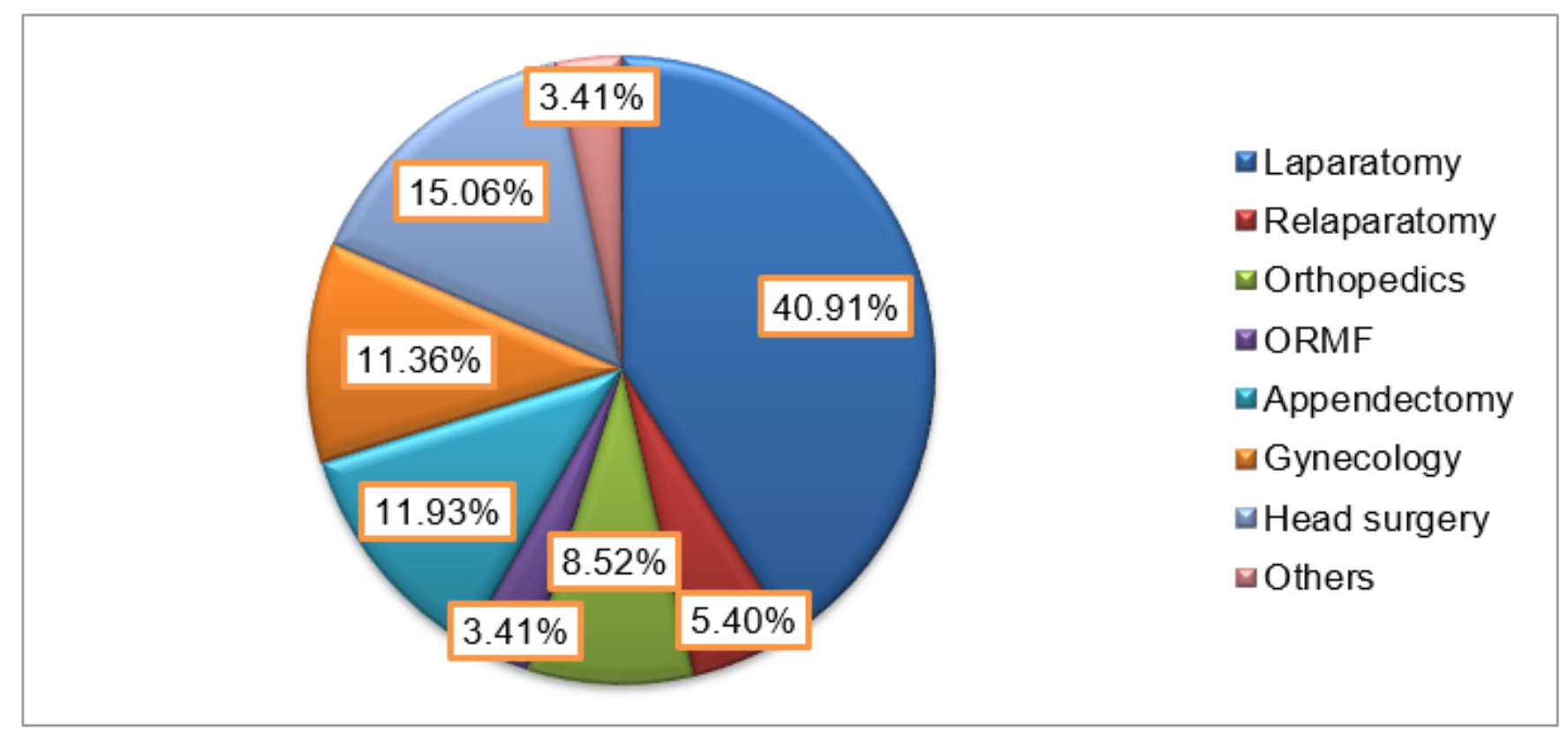

\section{Figure 2}

A pie chart delineates types of procedures done among study subjects at JMC, March 01 to May 30, 2021 


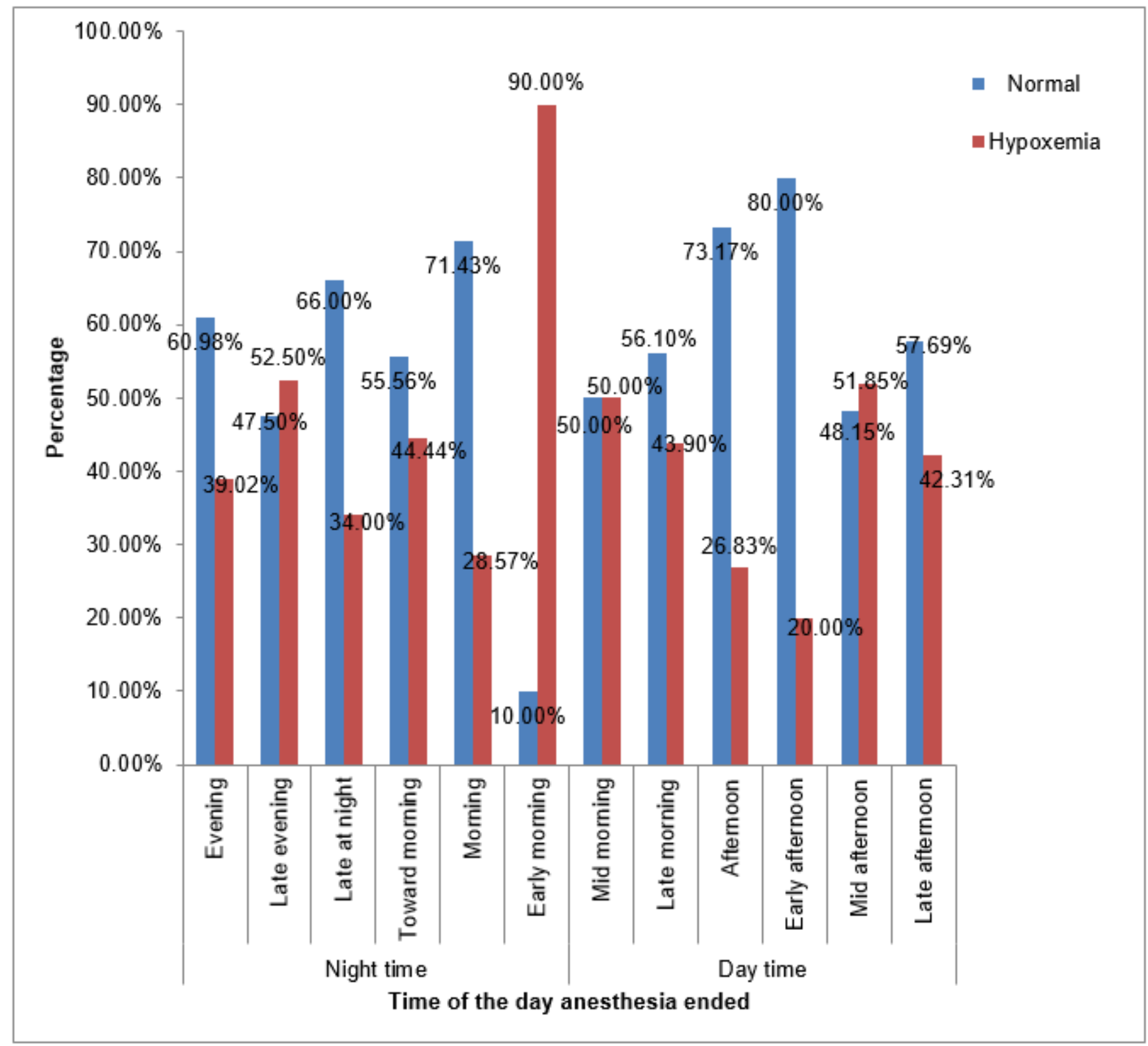

Figure 3

Distribution of EPH with different time anesthesia ended among patients who undergone emergency surgery under GA from March 01 to May 30, 2021 ( $N=352$ 